\title{
Biocontrol potential of Bacillus thuringiensis var. aizawai and Metarhizium anisopliae SPW isolate against insect pests of pechay and lettuce grown under protected and open field cultivation
}

\author{
Reny G. Gerona ${ }^{1 *}$ and Bernardita I. Lauro ${ }^{1}$
}

\begin{abstract}
Insect pests are one of the constraints in lettuce and pechay production. Although synthetic chemical insecticides are widely used, organic growers are interested in using alternative options which have no toxic residues. This study aimed to evaluate the biocontrol potential of Bacillus thuringiensis var. aizawai (Bta) and Metarhizium anisopliae (Ma) SPW isolate against insect pests of pechay and lettuce grown under protected and open field cultivation. Weekly spraying of each treatment was done using the recommended rates (RR) of application: Ma at $3 \mathrm{~L}$ spore suspension per $13 \mathrm{~L}$ water $\left(1 \times 10^{8}\right.$ spore concentration); Bta at $20 \mathrm{~g}$ per $16 \mathrm{~L}$ water; cypermethrin $5 \mathrm{EC}$ at $30 \mathrm{~mL}$ per $16 \mathrm{~L}$ water. Insect infestation was monitored weekly based on insect count and damage ratings. Yields were recorded at harvest. Results showed that application of either Bta, Ma or cypermethrin significantly reduced populations and damage of Spodoptera litura Fabr. and Plutella xylostella L. Pechay plants applied with Bta and Ma showed higher yields than cypermethrin in both types of cultivation. These findings suggested that Bta and Ma SPW isolate were effective against $S$. litura and $P$. xylostella and can be used as an alternative non-chemical option for their management.
\end{abstract}

Keywords: entomopathogens, alternative insect management, pechay, lettuce

\section{INTRODUCTION}

Pechay (Brassica rapa, Family: Brassicaceae) and lettuce (Lactuca sativa, Family: Asteraceae) are two of the leafy vegetables commonly grown by farmers. Just like other crops, insect pests are one of the constraints in lettuce and pechay production. In a study conducted in La Tranidad, Benguet, Tibao (2012) observed the following insect pests associated with pechay: Phyllotreta spp.(Chrysomelidae), Pieris rapae (Pieridae), Trichoplusia ni and Spodotera litura

${ }^{1}$ Visayas State University, Baybay City, Leyte, 6521-A, Philippines

\footnotetext{
* Corresponding Author. Address: Visayas State University, Baybay City, Leyte, 6521-A, Philippines; Email: rggerona@yahoo.com DOI: $10.32945 /$ atr39sb5.2017
} 
(Noctuidae), Liriomyza huidobrensis (Agromyzidae), Plutella xylostella (Plutellidae) and Myzus persicae (Aphididae). On the other hand, in the study of Oatman and Platner (1972) in Southern California, they found that Spodoptera exigua, Trichoplusia ni, Agrotis ipsilon and Feltia subterranea (Noctuidae) were the principal lepidopterous pests of lettuce. The lepidopterous species are the most damaging group. The adults lay eggs on the leaves and hatching caterpillars feed voraciously on leaves and heads of the plant. Reduction in yield and the downgrade of marketability of the crop is due to feeding damage, contamination by their presence or excreta on the leaves.

The use of synthetic insecticides is the common option that growers employ against vegetable insect pests. Two options that organic growers can also use are the biological pesticide, Bacillus thuringiensis (Bt) and entomopathogenic fungus, Metarhizium anisopliae (Ma) (Dutta 2015, Loc et al 2007). Bt is a soil bacterium that produces spores which contain endotoxins that have insecticidal activity. Their primary action is to lyse midgut epithelial cells by inserting into the target membrane and forming spores (Sanahuja et al 2011). Different strains of Bt have different insecticidal activity spectrums and were first used as an agricultural insecticide in the 1930ies. Bt kurstaki (Btk) and Bt aizawai (Bta), are commercial formulations that kill caterpillars. The endotoxin acts as a stomach poison and is dose dependent hence are more effective against early instars.

Bacillus thuringiensis var. kurstaki (Btk) and Bt aizawai (Bta) are used against lepidopterous larvae while other $B t$ strains are effective against species of beetles and dipterans. A commercial preparation of $B t k$ was effective in reducing caterpillar populations and insect feeding damage in cabbage and lettuce which was comparable to the standard chemical insecticide (lambda-cyhalothrin) (Zehnder et al 1997) and eggplant fruit and shoot borer (Cruda 2012).

Metarhizium anisopliae $(\mathrm{Ma})$ is a fungal pathogen that attacks a wide range of arthropods, more than 200 species from over 50 families (Ujjan \& Shahzad 2012). Ma was first recorded as an agricultural insecticide in the 1880's in Russia (Vega et al 2009). The general mode of infection of Metarhizium spp. comprises six stages in the following order: adhesion, germination, appressorium formation, penetration, colonization of haemolymph and extrusion and sporulation which can also be found in other entomopathogenic fungi (Moon San Aw \& Hue 2017). Ma also has strains with specific host ranges and various commercial formulations have been developed and registered for use. It was effective against the mealybug of tomato (Panyasiri et al 2007) and diamondback moth under laboratory and greenhouse conditions (Lo \& Chi 2007). Laboratory and field evaluations of Ma SPW isolate against the fruit borer of jackfruit proved to be effective thus recommended as one of the best options for its management (dela Cruz et al 2013) and against the eggplant fruit and shoot borer under greenhouse conditions (Cruda 2012).

For leafy vegetables like lettuce and pechay which are either eaten raw as green salads or with brief cooking, the use of alternative insect pest control like entomopathogens is a better option since they leave no toxic residues. However, local farmers still rely on the use of synthetic chemical insecticides as the only solution against insect pests of these vegetable crops. This study hypothesizes that entomopathogens like $B t$ and $M a$ are effective against lepidopterous and other insect defoliators of pechay and lettuce. Specifically, this study was conducted to evaluate the pest control potential of Bacillus thuringiensis var. aizawai and 
Biocontrol potential of Bacillus thuringiensis var. aizawai and Metarhizium anisopliae SPW

Metarhizium anisopliae SPW isolate against insect pests of pechay (Brassica rapa) and lettuce (Lactuca sativa) grown under protected and open field cultivation.

\section{MATERIALS AND METHODS}

\section{Experimental Sites (Protected and Open Field)}

This study was conducted under protective structure (ie, igloo type) and an open field at the experimental area of Visayas State University, Baybay City, Leyte, Philippines. The protective structure measuring $5 \mathrm{mx} 40 \mathrm{~m}$ and stands $4 \mathrm{~m}$ high was made up of coconut palm lumber covered with $0.002 \mathrm{~mm}$ thick UV-treated plastic film. An open field of similar dimension as the structure was used for the open field set-up. Both experimental sites were divided into two parts wherein the first half was planted with pechay while the second was planted with lettuce. The two experiments were simultaneously conducted from January-February, 2015.

\section{Land Preparation}

In both experimental set-ups, the soil was ploughed twice at one week interval followed by two harrowing. Three raised beds $(1 \mathrm{mx} 40 \mathrm{~m})$ were prepared at one meter apart in each set-up.

\section{Preparation of Seedlings}

Seeds of pechay (var. Pavo) and lettuce (var. Grande) were sown in seedling trays with sterilized soil mixture of garden soil, compost and carbonized rice hull $(2: 1: 1)$ and were placed in the nursery. One week before transplanting, seedlings were hardened.

\section{Transplanting and Fertilizer Application}

At two to three leaf stage (about two weeks old) seedlings were transplanted into the prepared beds at the rate of one seedling per hill at $30 \mathrm{~cm}$ distance between rows and $25 \mathrm{~cm}$ between hills. Basal application of complete fertilizer followed by weekly drenching of calcium nitrate were done following the recommended rate of 90-60-60kg N, P205, K20/ha.

\section{Water and Weed Management}

The plants were watered daily, usually in the morning, through drip irrigation. Weeds were removed manually two-three times monthly in the open field but usually only spot weeding under the protective structure due to scanty weed growth.

\section{Preparation of Ma SPW Isolate Spore Suspension}

Cultures of bagged Ma SPW isolate fungus were secured from the DA-RIARC, Balinsasayao, Abuyog, Leyte, Philippines. Spore suspension was prepared by adding $300 \mathrm{~mL}$ water with a pinch of neutral soap per bag and squeezed to dislodge 
the spores. Additional $800 \mathrm{~mL}$ of water was poured into the bag, shaken, squeezed and strained to extract a net of $1 \mathrm{~L}$ spore suspension per bag of cultured $M a$.

\title{
Application of Treatments
}

Treatment application was done weekly by spraying the test plants (60 for pechay and 52 for lettuce per replicate) at wetting capacity with a spray volume of $200-650 \mathrm{~mL}$ depending on the age/size of plants either early morning or late afternoon using the recommended rates (RR) of application for each treatment.

The treatments were:

$$
\begin{aligned}
\mathrm{T}_{0}= & \text { tap water } \\
\mathrm{T}_{1}= & \text { Metarhizium anisopliae }(\mathrm{Ma}) \mathrm{SPW} \text { Isolate at } 3 \mathrm{~L} \text { spore suspension } \\
& \text { per } 16 \mathrm{~L} \text { water }(\mathrm{RR}) \\
\mathrm{T}_{2}= & \text { Bacillus thuringiensis var. aizawai }(\mathrm{Bta}) \text { at } 20 \mathrm{~g} \text { per } 16 \mathrm{~L} \text { water }(\mathrm{RR}) \\
\mathrm{T}_{3}= & \text { Bta and } \mathrm{Ma} \text { at } \mathrm{RR} \text { applied at } 3 \text { day interval between sprays } \\
\mathrm{T}_{4}= & \text { cypermethrin } 5 \mathrm{EC} \text { at } 30 \mathrm{~mL} \text { per } 16 \mathrm{~L} \text { water }(\mathrm{RR})
\end{aligned}
$$

\section{Data Gathered}

Actual insect counts and damage ratings (adopted from Navasero \& Manipol 2005) were gathered weekly from 20 and 15 inner plants per replicate for pechay and lettuce, respectively. Yields (marketable \& non-marketable) were recorded at harvest.

\section{Damage Rating Scale for Chewing Insects}

Scale
0
1
3
5
7
9

\author{
Description \\ No damage \\ Leaf feeding on $1-5 \%$ of leaves \\ Leaf feeding on $6-15 \%$ of leaves \\ Leaf feeding on $16-25 \%$ of leaves \\ Leaf feeding on $26-50 \%$ of leaves \\ Leaf feeding on more than $50 \%$ of leaves
}

\section{Harvesting}

Harvesting was done early in the morning or late in the afternoon at $18-25$ (pechay) and 30-35 (lettuce) days after transplanting. The harvested crops were sorted into marketable and non-marketable yield.

\section{Experimental Design and Data Analysis}

The experiment was laid-out and arranged in Randomized Complete Black Design (RCBD) replicated three times. Data were analyzed using ANOVA following the Statistical Tool for Agricultural Research (STAR) version 2.0.1 and means were compared using Least Significant Difference at $5 \%$ level of significance. 
Biocontrol potential of Bacillus thuringiensis var. aizawai and Metarhizium anisopliae SPW

\section{RESULTS AND DISCUSSION}

Effects of Metarhizium anisopliae (Ma) SPW Isolate and Bacillus thuringiensis var. aizawai (Bta) on insect pests of pechay

Low numbers of cluster caterpillar (Spodoptera litura Fabr.) and the diamondback moth (Plutella xylostella L.) were observed throughout the cropping period. Figures 1-4 show that under protective structure, generally all treatments got significantly lower damage ratings and population counts than the control except for $S$. litura in cypermethrin treated plots, particularly during weeks 2 and 3 . During this period, lower damage ratings and population counts of $S$. litura were recorded in three biological treatments compared to the cypermethrin treated plots. In the open field, higher damage ratings and population counts were also obtained in the water sprayed control compared to the rest of the treatments especially with $P$. xylostella. However, cypermethrin usually had lower damage ratings and population counts than the biological treatments, particularly in the weeks 3 and 4 observations. Weekly rainfall ranged from $13-32 \mathrm{~mm}$ (Figure 5) and may have washed the field applied Bta and Ma off more easily than the cypermethrin.
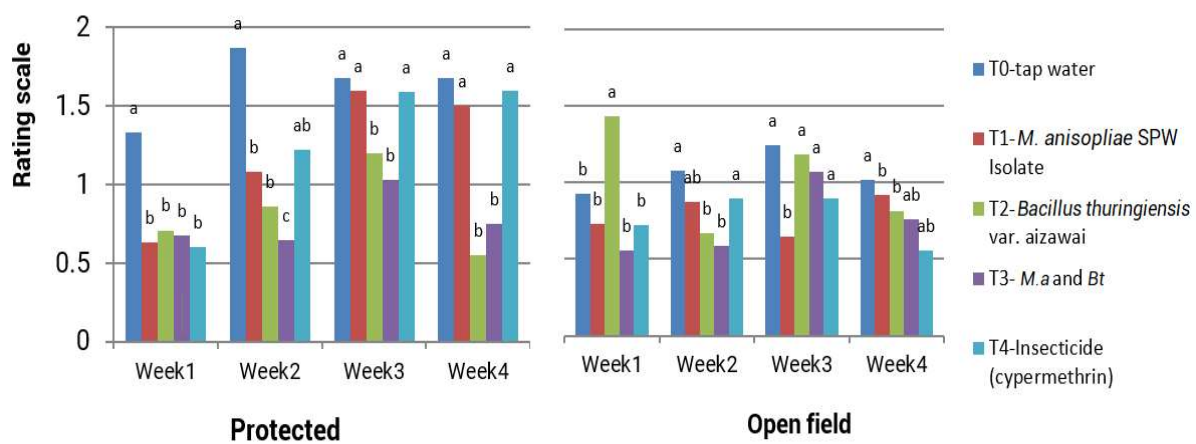

Figure 1. Mean damage ratings of cluster caterpillar (Spodoptera litura Fabr.) on pechay under protected and open field cultivation

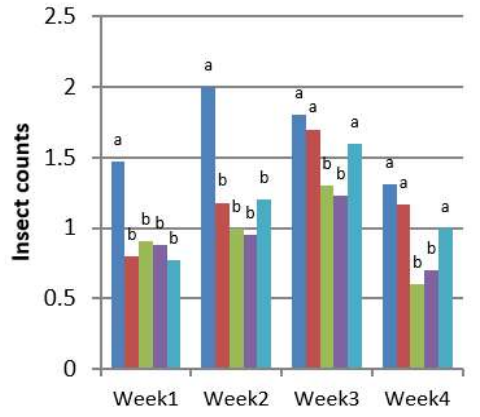

Protected

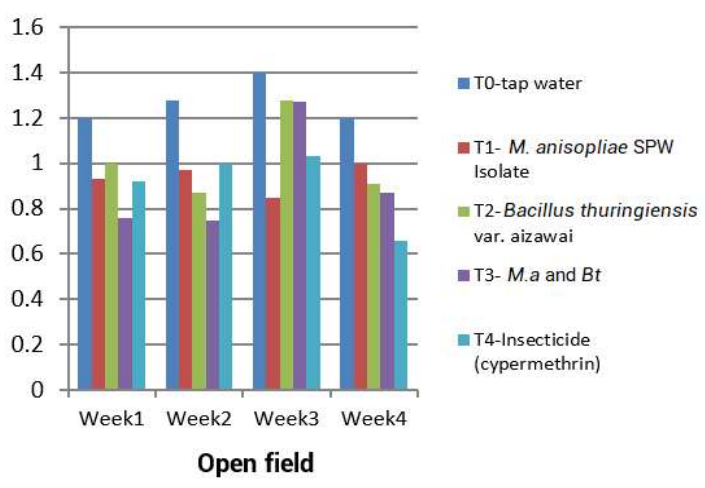

Figure 2. Mean population counts of cluster caterpillar (Spodoptera litura) on pechay under protected and open field cultivation 


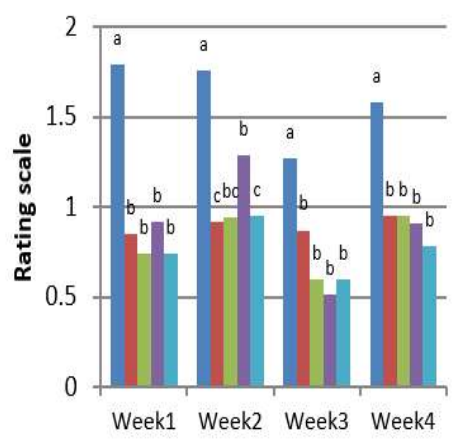

Protected

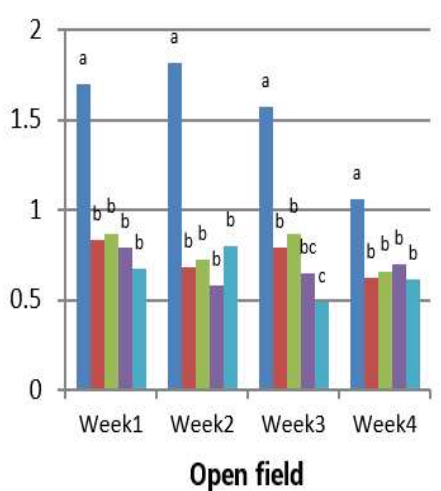

T0-tap water

-T1- M. anisopliae SPW Isolate

$=\mathrm{T} 2$ - Bacillus thuringiensis

var. aizawai

-T3- M. $a$ and Bt

- T4-Insecticide

(cypermethrin)

\section{Open field}

Figure 3. Mean damage rating of diamondback moth on pechay under protected and open field cultivation
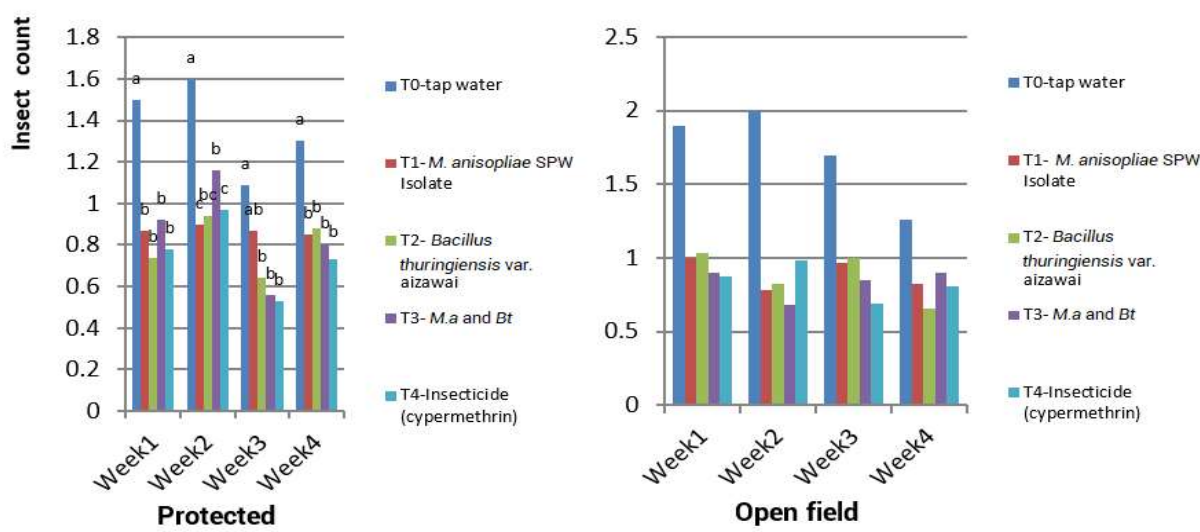

Figure 4. Mean population counts of diamondback moth on pechay under protected and open field cultivation

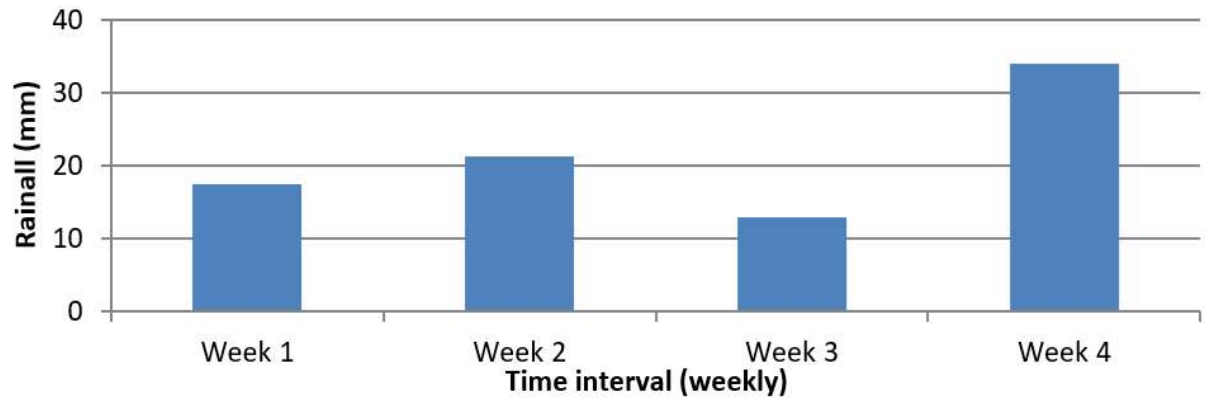

Figure 5. Weekly rainfall $(\mathrm{mm})$ during the cropping period 
Biocontrol potential of Bacillus thuringiensis var. aizawai and Metarhizium anisopliae SPW

\section{Effects of Metarhizium anisopliae SPW Isolate and Bacillus thuringiensis var. aizawai on insect pests of lettuce}

The insect infestation of lettuce was minimal compared to pechay during the cropping period. Spodoptera litura was the only species observed damaging lettuce. Figure 6 shows that damage ratings in all treatments were significantly lower than those in the control (TO) in both types of cultivation. This result indicated that Ma SPW and Bta were as effective as the insecticide (cypermethrin) against Spodoptera litura. Infected larvae were observed wherein late instars were not able to complete pupation (Figure 7).
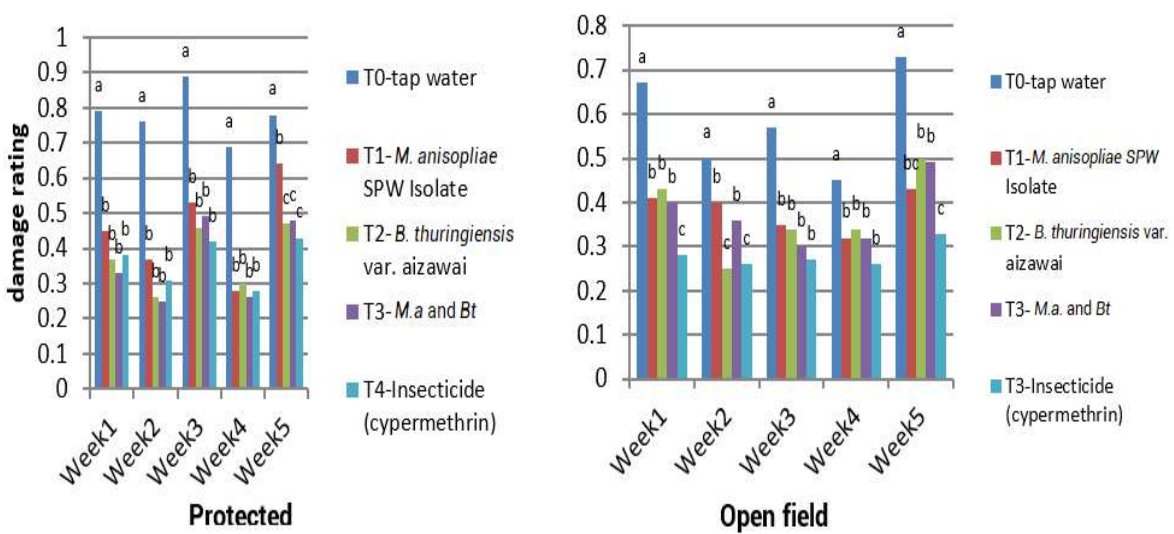

Figure 6. Mean damage ratings of cluster caterpillar (S. litura) on lettuce under protected and open field cultivation

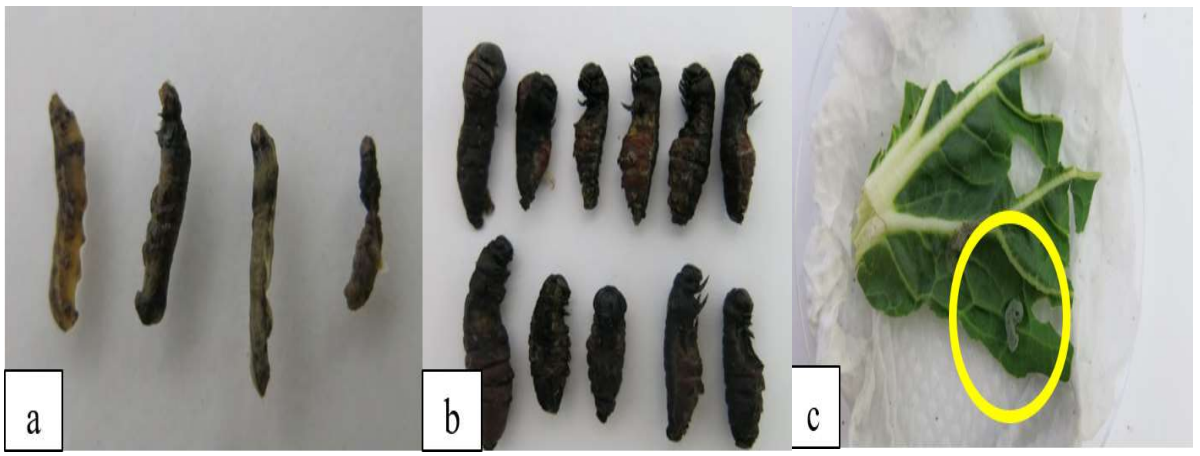

Figure 7. Infected early instar (a) and late instar (b) larvae of S. litura with Bta; (c) infected larva of S. litura with Ma SPW isolate

The effectiveness of Bta and Ma shown in this study was in consonance with some reported studies. Similar results were reported by Mau et al (2016) who investigated the effect of Bta against $P$. xylostella on cabbage. They found that Bta provided moderate levels of control which was better than the conventional insecticides used. In a related study, Wanna et al (2012) reported moderate toxicity of Bta against Helicoverpa armigera under laboratory and potted experiments. 
Furthermore, Freed et al (2012) mentioned that entomopathogenic fungi are efficient tools in the biocontrol of a wide range of insect pests particularly in agricultural crops. In their investigation, Ma was effective against Spodoptera exigua.

\section{Yield of Pechay and Lettuce as Affected by the Different Treatments Under Protected and Open Field Cultivation}

Pechay grown under protected cropping had up to three times greater yield than those grown in the open field (Figure 8). The only significant treatment differences in yield were observed in plants grown under protective structures (Table 1). Plant survival ranged from $40 \%$ in the water sprayed treatments to $72 \%$ in the Bta sprayed treatment. Highest marketable yields by both number and weight were obtained with weekly Bta sprays $(46,10.3 \mathrm{~kg})$ or the weekly Bta and Ma sprays $(43,9.4 \mathrm{~kg})$ followed by Ma sprays alone $(34,7.3 \mathrm{~kg})$ and weekly cypermethrin sprays $(29,6.5 \mathrm{~kg})$. The water sprayed control yielded $4.3 \mathrm{~kg}$, less than half the yield of the Bta plots with lower plant survival. Lowest yield was observed in water sprayed control. However, it was noted that fewer plants in control survived as shown in Table 1 due to bacterial wilt incidence. The non-marketable plants recorded were mainly damaged by insects wherein the $\mathrm{Ma}$ (T2) and Bta (T3) treated plots had the lowest number and weight obtained. Results indicated that differences in yield were not only due to the effects of treatments on insect pests and uneven number of surviving plants but also on the cropping systems. The highest yields were obtained under structure (Figure 8). Plants were growing well and with greener leaves under protected cultivation than in the open field (Figure 9). This observation supported the findings of Gonzaga et al (2012) that generally vegetable crops have better performance under protective structure than in the open field particularly during the rainy season. However, in lettuce, yields were just comparable between treatments and types of cultivation which could be due to the low level of insect infestation observed. In addition, unlike pechay, lettuce plants were growing well in both types of cultivation (Figure 9) which was probably favoured by the cooler climate brought by the scattered rainfall throughout the season (Figure 5).

Table 1. Mean number and weight of marketable and non-marketable pechay plants under protected cultivation

\begin{tabular}{lcccc}
\hline \multirow{2}{*}{ Treatment } & \multicolumn{3}{c}{ Marketable plants } & Non-marketable plants \\
\cline { 2 - 5 } & Number & $\begin{array}{c}\text { Total Weight } \\
(\mathrm{kg})\end{array}$ & $\begin{array}{c}\text { Head wt/ } \\
(\mathrm{g})\end{array}$ & Weight $(\mathrm{kg})$ \\
\hline T0-Tap water & $24^{\mathrm{b}}$ & $4.3^{\mathrm{c}}$ & 179 & $4.7^{\mathrm{a}}$ \\
T1-M. anisopliae SPW Isolate & $34^{\mathrm{ab}}$ & $7.3^{\mathrm{ab}}$ & 215 & $3.3^{\mathrm{ab}}$ \\
T2-B. thuringiensis var. aizawai & $46^{\mathrm{a}}$ & $10.3^{\mathrm{a}}$ & 224 & $1.2^{\mathrm{c}}$ \\
T3-M.a. and Bt & $43^{\mathrm{a}}$ & $9.4^{\mathrm{a}}$ & 219 & $1.7^{\mathrm{bc}}$ \\
T4-Insecticide (Cypermethrin) & $29^{\mathrm{b}}$ & $6.5^{\mathrm{b}}$ & 224 & $4.8^{\mathrm{a}}$ \\
CV\% & 19.5 & 29.1 & & 32.9 \\
\hline
\end{tabular}


Biocontrol potential of Bacillus thuringiensis var. aizawai and Metarhizium anisopliae SPW

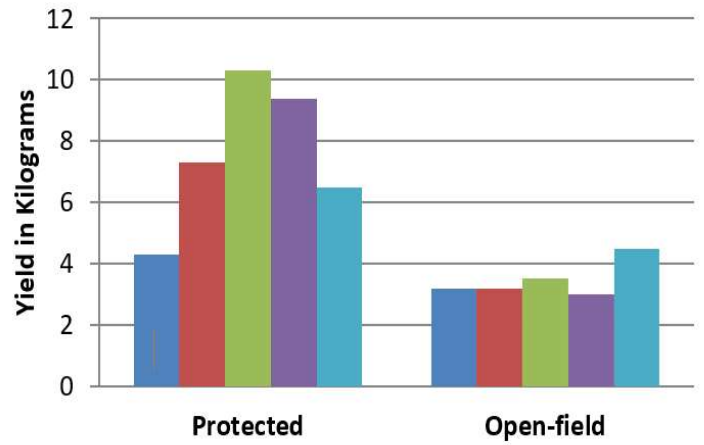

- T0-Tap water

T1-M. anisopliae SPW Isolate

- T2-B. thuringiensis var. aizawai

- T3-M.a and Bt

n T4-Insecticide (Cypermethrin)

Figure 8. Mean weight of marketable pechay plants harvested under protected and open-field and protective cultivation

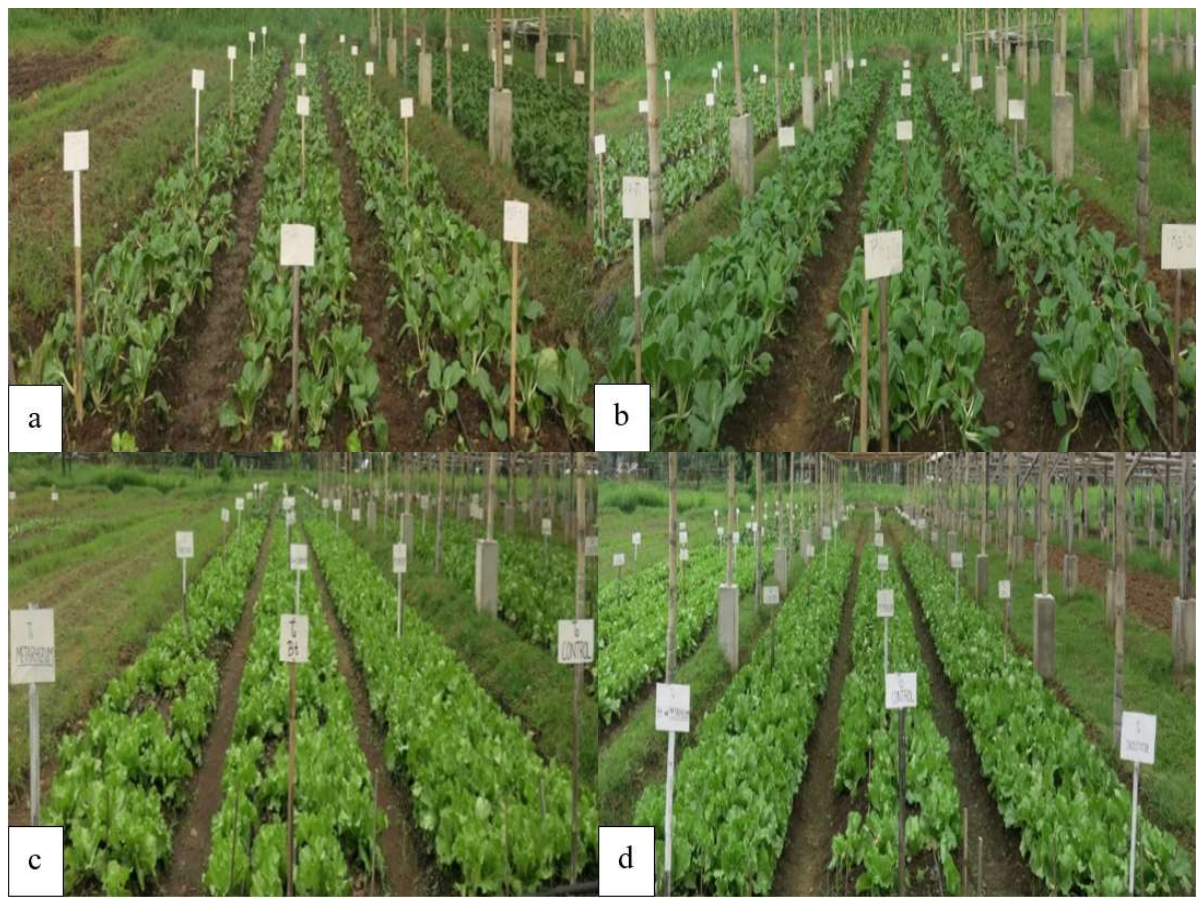

Figure 9. Experimental set-up at three weeks after transplanting: pechay open field (a) and protected (b); lettuce open field (c) and protected (d)

\section{CONCLUSION}

This study has shown that Bta and Ma SPW isolate were effective against the $S$. litura and $P$. xylostella of pechay and $S$. litura of lettuce grown under protected and open field cultivation. Applications of Bta, $\mathrm{Ma}$ and cypermethrin significantly reduced insect pest populations and damage compared to control water sprayed 
plants. Pechay plants applied with Bta and Ma showed higher yields than cypermethrin in both types of cultivation. These findings suggest that Bta and $\mathrm{Ma}$ can be used as an alternative non-chemical option for the management of $S$. litura and $P$. xylostella in pechay and lettuce. Lepidopterous pests are a problem for many vegetables in the Southern Philippines and further research to test the efficacy of Bta could see it as a viable alternative to broadspectrum synthetic pyrethroid insecticides. Ma has potentially a wider host range and efficacy research on how broad the Ma SPW isolate host range, including its impact on beneficial, would be helpful to determine where it fits within an integrated pest management strategy for vegetable production in the Southern Philippines. Flea beetles can be a significant pest of pechay and testing one of the Bt strains with coleopteran activity could see the removal of the need for any broadspectrum insecticides in the production system. In the Southern Philippines the only significant pests of lettuce are lepidopterous hence it is possible to grow lettuce without any need for broadspectrum insecticides.

\section{ACKNOWLEDGEMENT}

The authors would like to thank the Australian Center for International Agricultural Research (ACIAR) for the financial support; Dr. Sandra McDougall, Australian Project Leader, ACIAR ICM Project, for the valuable corrections/ suggestions/comments for the improvement of this paper.

\section{REFERENCES}

Cruda KMB. 2012. Efficacy of Metarrhizium anisopliae (Metsch.) Sorokin and Bacillus thuringiensis Berliner against eggplant fruit and shoot borer Leucinodes orbonalis Guenee (Lepidoptera: Pyralidae) (Undergraduate thesis) (pp36). Visayas State University, Visca, Baybay City, Leyte

Dela Cruz CS, Gapasin RM, Gerona RG, Almeroda BB, Tisado MSP \& Agres MBL. 2013. Biological control of jackfruit fruit borer using a friendly fungus, Metarhizium anisopliae SPW isolate. PCAARRD Info Bull 34(11)

Dutta S. 2012. An ecofriendly approach for pest control. World journal of pharmacy and pharmaceutical sciences. SJIF Impact Factor 5.210 4(6):250-265. Review Article ISSN 2278-4357. Deptartment of Pharmacology, NSHM College of Pharmaceutical Technology, NSHM Knowledge Campus, Kolkata- Group of Institutions, 124(60). B.L.Saha Road, Kolkata-700053

Ekesi S, Maniania NK, Ampong-Nyarko K \& Onu I. 1999. Effect of Intercropping Cowpea with Maize on the Performance of Metarhizium anisopliae Against Megalurothrips sjostedti (Thysanoptera: Thripidae) and Predators. Environmental Entomology 28(6):1154-1161. doi:http://dx.doi.org/10/1093/ee/28.6.11541154-1161

Freed S, Ahmad Saleem M, Khan MB \& Naeem M. 2012. Prevalence and Effectiveness of Metarhizium anisopliae Against Spodoptera exigua (Lepidoptera: Noctuidae) in Southern Punjab, Pakistan University College of Agriculture, Bahauddin Zakariya University, Multan, Pakistan. Pakistan Journal of Zoology 44(3):753-758 
Biocontrol potential of bacillus thuringiensis var. aizawai and Metarhizium anisopliae SPW

Gonzaga ZC. 2012. Low-cost Protected Cultivation: Enhancing Year-round Production of High-value Vegetables in the Philippines (pp123-137). In Oakshott J and Hall D (eds) Smallholder HOPES-horticulture, people and soil. 2013. Referred proceedings of the ACIAR-PCAARRD Southern Philippines Fruits and Vegetables Program Meeting, 3 July 2012, Cebu, Philippines. ACIAR Proceedings 139 (pp298). Australian Centre for International Agricultural Research: Canberra. (ISBN 978-1-922137-42-5 (print)); (ISBN 978-1-922137-432 (online)

Loc NT and Chi VTB. 2007. Biocontrol and potential of Metarhizium anisopliae and Beauveria bassiana against diamondback moth, Plutella xylostella. Omonrice 15:86-39

Mau R, Dunbar DM, Gusukuma-Minuto L \& Shimabuku RS. 2016. Management of diamondback moth with emamectin benzoate and Bacillus thuringiensis subsp. aizawai insecticides.Retrieved:June7,2016. http://web.entomology. cornell.edu/shelton/diamondbackmoth/pdf/1996papers/1996DBM29.pdf

Moon San AWK and Hue SM. 2017. Mode of infection of Metarhizium spp. fungus and their potential as biological control agents. Journal of Fungi 3:1-30

Oatman ER and Platner GR. 1972. An ecological study of lepidopterous pests affecting lettuce on Coastal Southern California. Environmental Entomology 1:202-204

Panyasiri C, Attathom T \& Poehling HM. 2007. Pathogenicity of entomopathogenic fungi-potential candidates to control insect pest on tomato under protected cultivation in Thailand. Journal of Plant Disease and Protection 114(6):278-287

Polanczyk A, Pires da Silva RF \& Fiuza LM. 2000. Effectiveness of Bacillus thuringiensis strains against Spodoptera frugiperda (lepidoptera: noctuidae). http://dx.doi.org/10.1590/S1517-83822000000300003. Brazilian Journal of Microbiology 31(3)

Sanahuja G, Banakar R, Twyman RM, Capell T \& Christou P. 2011. Bacillus thuringiensis: A century of research, development and commercial applications. Plant Biotechnology Journal 9:283-300

Tibao Marlon Y. 2012. Insect Pests Succession of Organically Grown Pechay (Brassica chinensis Linnaeus) (Undergraduate thesis). Benguet State University, La Trinidad, Benguet, Philippines

Ujjan AA and Shahzad S. 2012. Use of entomopathogenic fungi for the control of mustard aphid (Lipaphic erysimi) on canola (Brassica napus L.). Pakistan Journal of Botany 44(6):208-2086

Vega FE, Goettel MS, Blackwell M, Chandler D, Jackson MA, Keller S, Koike M, Maniania NK, Monzón A, Ownley BH, Pell JK, Rangel DEN \& Roy HE. (2009) Fungal entomopathogens: New insights on their ecology. Fungal Ecology 2:149159

Wannar R, Zhihong X \& Haixin Y. 2012. Helicoverpa armigera(Lepidoptera: Noctuidae) and its contact toxicity to pupae and adults of parasitoid Microplitis mediator (Hymenoptera: Braconidae). Acra Entomological Sinica 55(8):941949.Retrieved: June7,2016: http://www.insect.org.cn/EN/volumn/ current.shtml 